\title{
An Obstructive Prostatic Urethral Calculus in a Patient with Urethral Strictures: A Case Report
}

\author{
Sule MB ${ }^{1 *}$, Shamaki AMB ${ }^{1}$, Umar AU ${ }^{2}$, Gele IH $^{3}$, Yakubu BS ${ }^{3}$, Ribah MM ${ }^{3}$ and Aliyu AZ ${ }^{3}$ \\ ${ }^{1}$ Department of Radiology, Usmanu Danfodiyo University, Sokoto. \\ ${ }^{2}$ Department of Radiology, Gombe State University, Gombe. \\ ${ }^{3}$ Department of Radiology, Usmanu Danfodiyo University Teaching Hospital, Sokoto.
}

*Corresponding author: SULE Muhammad Baba, Department of Radiology, Usmanu Danfodiyo University, Sokoto. Received date: June 07, 2021; Accepted date: June 12, 2021; Published date: June 16, 2021

Citation: Sule MB, Shamaki AMB, Umar AU, Gele IH, Yakubu BS, et al (2021). An Obstructive Prostatic Urethral Calculus in a Patient with Urethral Strictures: A Case Report. J Clinical Research and Reports, 8(3); DOI:10.31579/2690-1919/178

Copyright: (C) 2021 Sule Muhammad Baba, This is an open access article distributed under the Creative Commons Attribution License, which permits unrestricted use, distribution, and reproduction in any medium, provided the original work is properly cited.

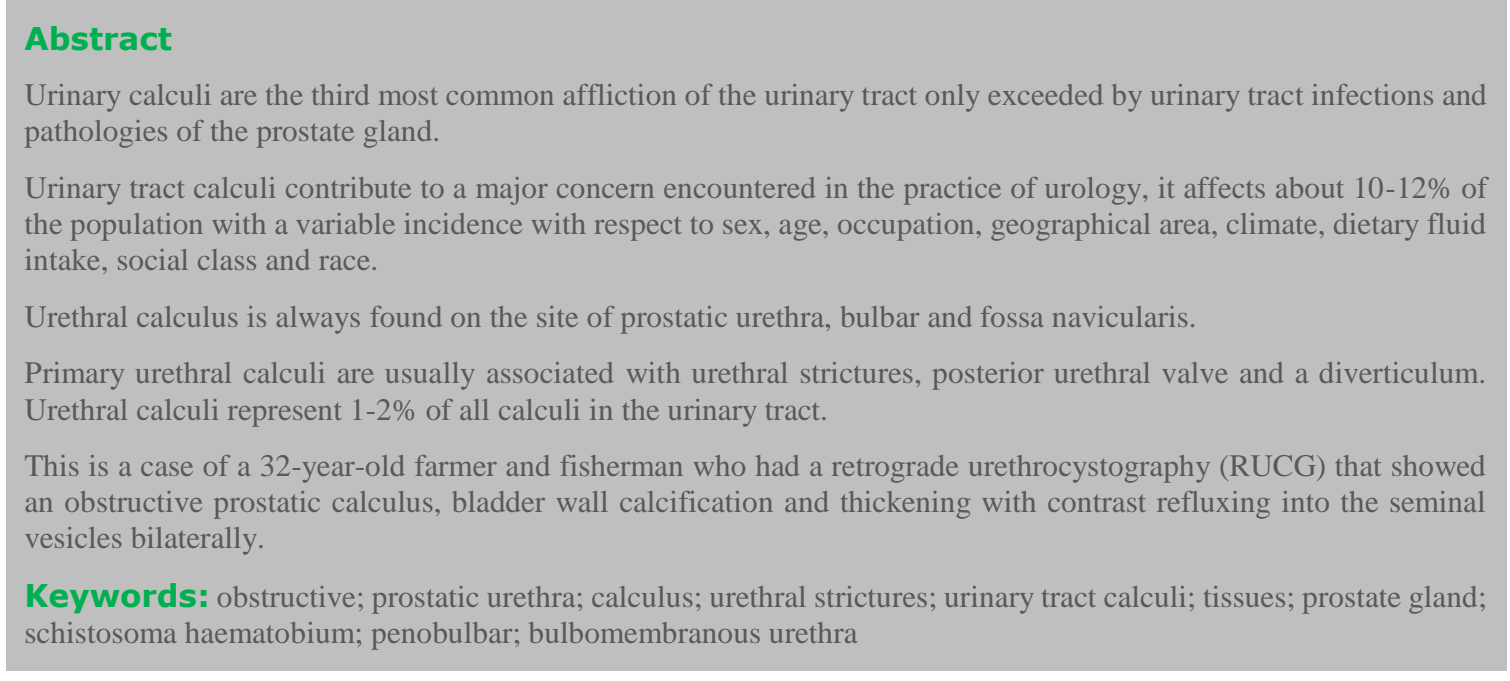

\section{Introduction}

Urinary tract calculi contribute to a major concern encountered in the practice of urology, it affects about $10-12 \%$ of the population with a variable incidence with respect to sex, age, occupation, geographical area, climate, dietary fluid intake, social class and race [1-4].

Primary urethral calculi are usually associated with urethral strictures, posterior urethral valve and a diverticulum. Urethral calculi represent 1$2 \%$ of all calculi in the urinary tract [4-6].

Primary prostatic urethral calculi are extremely rare especially the huge/giant forms and should not be confused with true prostatic calculi which develop in the acini or tissues of the prostate gland [7].

Urethral calculi are most commonly located in the prostatic urethra proximal to the narrow membranous portion [4].

Urinary calculi are the third most common affliction of the urinary tract only exceeded by urinary tract infections and pathologies of the prostate gland $[3,4,6]$.
Urethral calculi usually originate from the bladder and less often from the upper urinary tracts, it is either primary or autochthonous urethral calculi arising proximal to urethral strictures or associated with a urethral diverticulum and urethrocele or secondary (migratory) urethral calculi from bladder or renal calculi $[6,8]$.

Primary or autochthonous urethral calculi are less often seen in females and if seen are almost often accompanied with an underlying genitourinary pathology like stricture or urethral diverticulum $[6,9,10]$.

Posterior urethral calculi were further classified into three categories by Swift Joly [11] as either:

1. Vesico-Urethral Stones: these calculi are located partly in the urinary bladder and partly in the posterior urethra.

2. Urethral Stones: these calculi are located in the urethra alone.

3. Urethro-Prostatic calculi: these calculi lie partly in the preformed cavity in the prostate gland.

Prostatic urethral calculi occur more in younger male while true prostatic calculi are usually associated with older men aged beyond 50 years [12]. 
Urethral calculi are very rare in the female sex due to low incidence of bladder calculi and short urethra [7,13].

Predisposing factors for insitu formation of urethral calculi are the presence of strictures, diverticulum, hypospadias and urethral meatal stenosis $[7,14,15]$.

Symptomatic prostatic urethral calculus often require treatment, this basically entail surgical removal following transurethral electro-resection loop or holmium laser [16].

\section{Case Report}

This is a case of a 32-year-old farmer and fisherman who presented with dysuria, frequency, terminal hematuria, reduced urinary volume, urethral discharge, feeling of a hard mass in the perineum and poor ejaculation for almost 2 years duration.

The patient is oriented and conscious, not pale, anicteric, not dehydrated, not in obvious respiratory difficulty and no pedal edema.

The case had a retrograde urethrocystography (RUCG) that showed bladder wall calcification and thickening with an oval opacity measuring about $25 \mathrm{~mm} \times 20 \mathrm{~mm} \times 20 \mathrm{~mm}$ in craniocaudal, mediolateral and anteroposterior dimensions in the region of the prostatic urethra on the preliminary film of the RUCG (Figure 1).

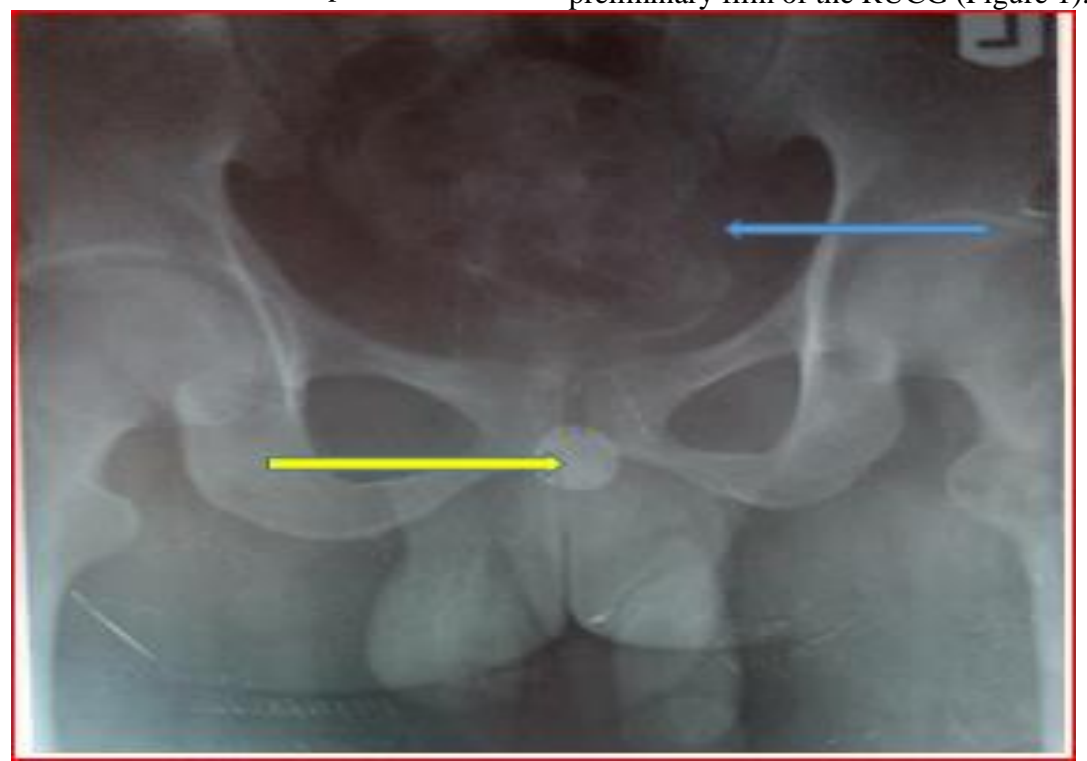

Figure 1: Preliminary film of RUCG showing a centrally placed opacity of calcific density with peripheral curvilinear calcification most likely contracted bladder with bladder wall calcification (left blue arrow), an oval calcific density opacity centrally below the symphysis pubis; the posterior urethral calculus (right yellow arrow). The demonstrated bones and joints show some degenerative changes.

The contrast films showed annular strictures at the penobulbar and bulbomembranous junctions, oval filling defect in the region of the prostatic urethra the; obstructive prostatic calculus, dilatation and ballooning of the prostatic urethra, contrast refluxing into the seminal vesicles bilaterally more marked on the left side. See figures 2-4.

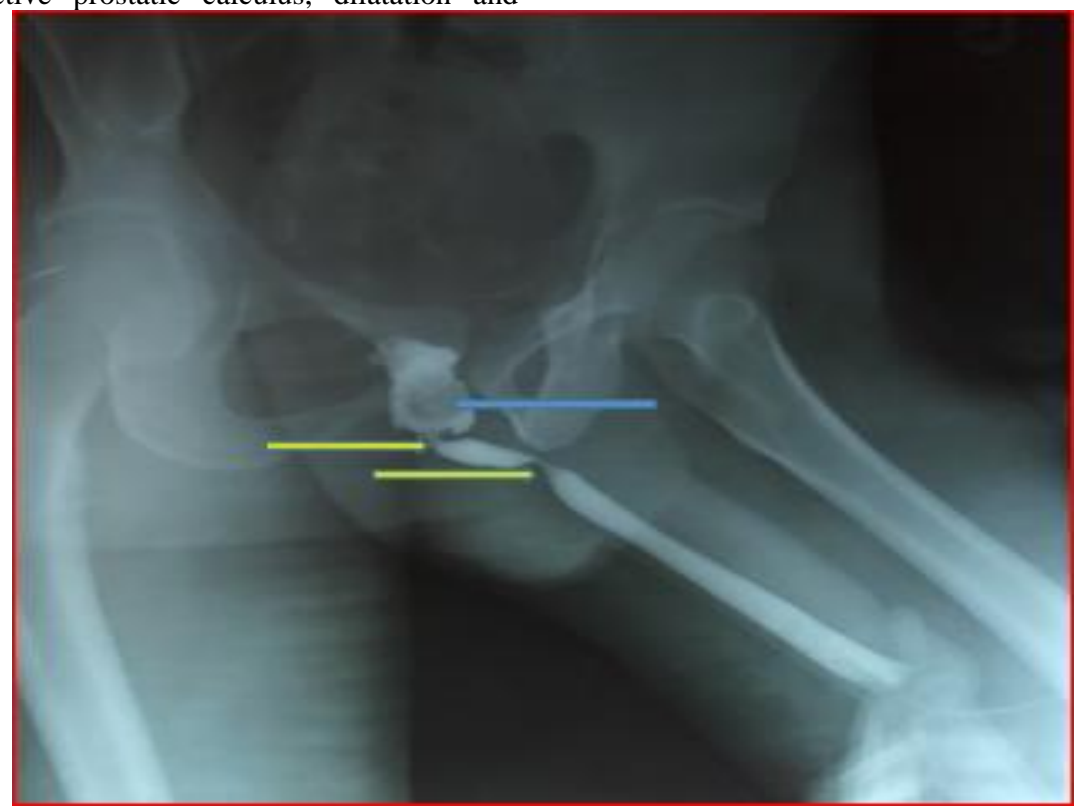

Figure 2: Contrast image of an RUCG showing severe annular strictures at the peno-bulbar urethral junction and bulbo-membranous urethral junction (right yellow arrows) with an oval filling defect at the posterior urethral valve region; the calculus (left blue arrow). 


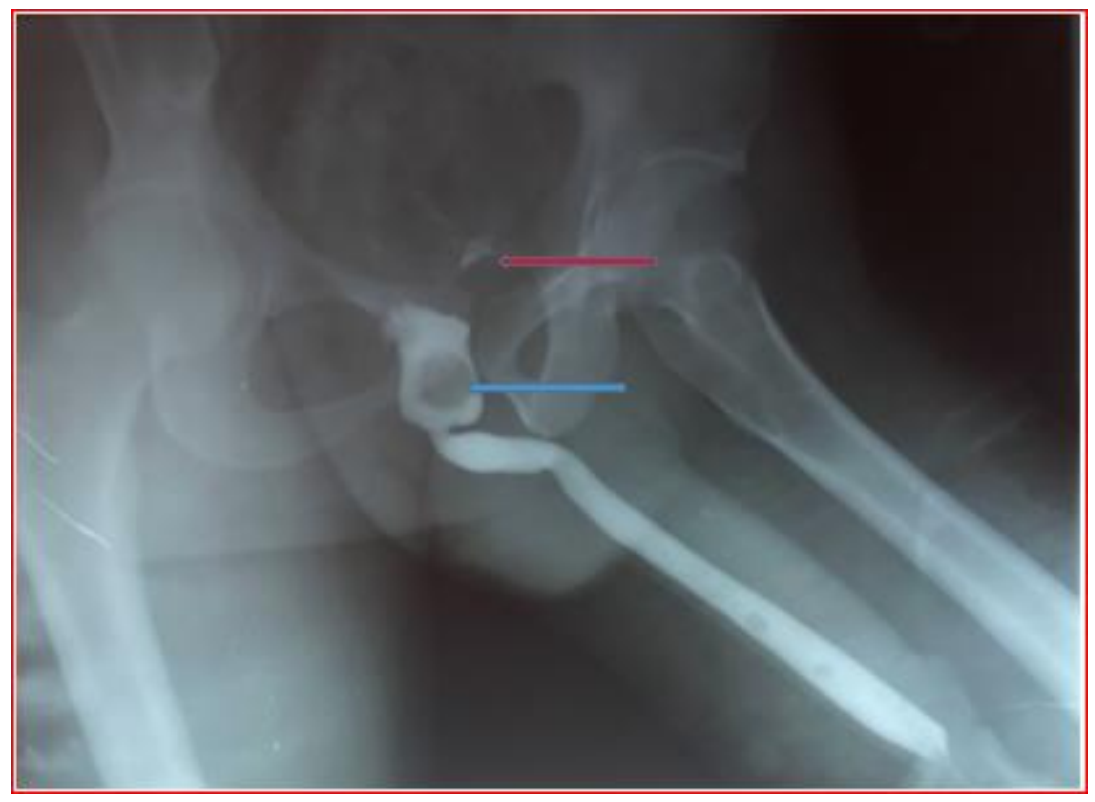

Figure 3: Contrast image of an RUCG showing the annular strictures at the peno-bulbar urethral junction and bulbo-membranous urethral junction with an oval filling defect at the posterior urethral valve region; the calculus (left blue arrow) and early contrast reflux in to the seminal vesicles bilaterally more on the left side (left red arrow).

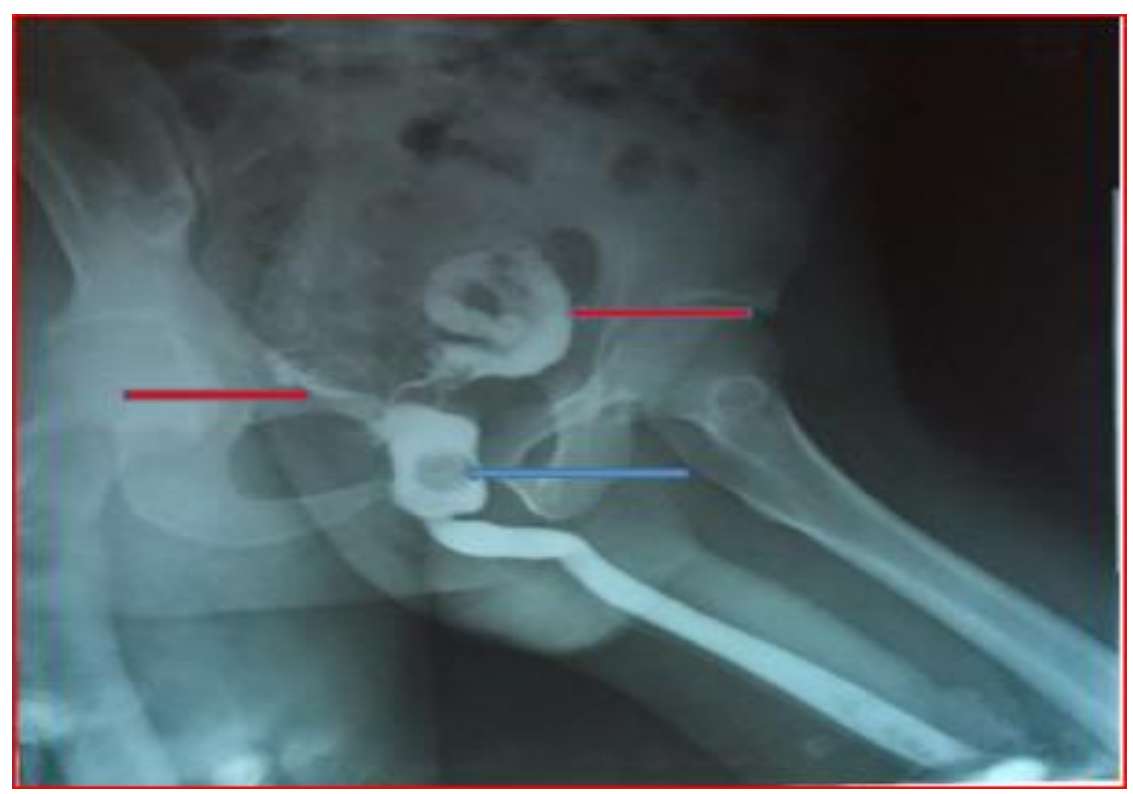

Figure 4: Contrast image of an RUCG showing the annular strictures at the peno-bulbar urethral junction and bulbo-membranous urethral junction with an oval filling defect at the posterior urethral valve region; the calculus (left blue arrow). And contrast reflux in to the seminal vesicles bilaterally more marked on the left side (right and left red arrows).

All efforts to demonstrate the bladder became abortive due to patients' discomfort and excruciating pain during the examination.

Abdominopelvic ultrasound scan showed a thick-walled urinary bladder with calcific crust in the wall with bilateral hydroureteronephrosis (dilatation of the ureters and collecting systems of the kidneys).

The patient also came with result of microscopy, culture and sensitivity of the urine and urethral discharge that confirmed the presence of Schistosoma haematobium.
The patient was also been prepared for surgical removal of the prostatic calculus, but as at the time of the report he has not consented to the treatment option made available to him.

We report the radiological findings of this case due to its peculiarity in the practice of radiology and urology.

\section{Discussion}

Posterior urethral strictures are rare and are seen more in the male gender; this case is a male. Urethral calculi are also more common in the prostatic region following strictures or diverticulum; the index case is that of a 
prostatic calculus with associated strictures at the penobulbar and bulbomembranous urethra.

Posterior urethral calculi may follow infective conditions/processes, the index case had radiological, clinical and laboratory features of Schistosomiasis.

Urethral calculi may be associated with the occupation of the subjects as documented in most literatures; this patient happens to be a farmer and fisherman; these are occupational hazards towards infestation by Schistosoma. The index patient was a confirmed case of Schistosomiasis which is believed to have caused the urethral strictures predisposing to the prostatic calculus.

Urolithiasis especially in the urethra often present with varying symptoms like dysuria, hematuria, frequency, incomplete feeling of voiding, perineal hard mass, urethral discharge etc; our index case also presented with most features documented in the literature.

The radiological findings documented in the literature that is often associated with patients suffering from prostatic calculi may be demonstration of a calculus most often in the prostatic urethra, accompanying narrowing of the proximal urethra; strictures, bladder wall thickening, affectation of the upper tracts to mention but a few; the index case also had such findings with associated reflux of contrast in to the seminal vesicles bilaterally most likely from severe obstructive effect of the prostatic calculus that measured about $25 \mathrm{~mm} \times 20 \mathrm{~mm} \times 20 \mathrm{~mm}$ in diameter.

Urethral calculi have been classified as either primary or secondary; the index case is most likely primary because no other associated calculi or features to suggest migration were demonstrated.

Long standing urethral calculus may be complicated by fistulous or sinus tracts, diverticulum and features of obstructive uropathy and subsequently obstructive nephropathy. The index case also presented with some of these features except for obstructive nephropathy.

In the literature, symptomatic prostatic urethral calculus often require treatment, this basically entail surgical removal following transurethral electro-resection loop or holmium laser. The index case was also advised on surgical removal of the prostatic calculus, thereby conforming to that reported in the literature.

\section{Conclusion}

Prostatic calculi may be associated with occupation of the patients, the commonest occupation in this environment is predominantly farming. Prophylactic intervention against Schistosoma may reduce the incidence of urinary schistosomiasis thereby reducing the probability of urethral stricture and subsequent calculi formation.

\section{References}

1. Arias FF, Garcia CE, Lovaco CF, Escudero BA, Avila PS, Villar PJ (2000). Epidemiology of urinary lithiasis in our Unit. Clinical course in time and predictive factors. Arch Esp Urol. 53:343-347.

2. Sorokin I, Mamoulakis C, Miyazawa K, Rodgers A, Talati J, Lotan Y (2017). Epidemiology of stone disease across the world. World J Urol. 17:1.

3. Prezioso D, Strazzullio P, Lotti T Bianchi G, Borghi L, Caione $P$, et al (2015). Dietary treatment of urinary risk factors for renal stone formation. A review of CLU working Group. Arch Ital Urol Androl. 87:105-120.

4. Vinod KP, Rahul Tiwari, Ramakrishnan K (2013). A Giant Dumbbell Shaped Vesico-Prostatic Urethral Calculus: A Case Report and Review of Literature. Case Reports in Urology. 2013:1-5.

5. Koga S, Arakaki Y, Matsuoka M, Ohayama C (1990). Urethral calculi. British Journal of Urology. 1990;65:288-289.

6. Ameen AA, Kegham HH, Abid AH, (2007). Evaluation and management of urethral calculi. Int Surg J. 2007; 4:2392-2396.

7. Agarwai A, Sigdel G, Belokar WK (2012). Arare case of giant urethral calculus and multiple urethral diverticulum. J Coll Med Sci. 2012; 8:46-48.

8. Shanmugam TV, Dhanapal V, Rajaraman T, Chandmsekar C, Balashanmugam P (2000). Giant urethral calculi. Hospital Medicine. 2000; 61:582.

9. Ahmed A, Saeed NM (2008). Experience with the management of urethral stones presenting with urinary retension at Gusau. Niger J Clin Pract. 2008; 11:309-311.

10. Akhtar J, Ahmed S, Zamir N (2012). Management of impacted urethral stones in children. J Coll Physicians Surg Pak. 2012; 22:510-513.

11. Barrett JC (1957). Giant prostatic caculi. British Journal of Surgery. 1957; 45:267-269.

12. Bedir S, Kilciler OA, Erdemir F, Avci A, Ozgok Y (2005). Endoscopic treatment of multiple prostatic calculi causing urinary retension. International Journal of Urology. 2005; 12:693-695.

13. Win T (1994). Giant urethral calculus: Singapore Med J .1994; 35:4-5.

14. Hegele A, Olbert P, Wille S (2002). Giant calculus of the posterior urethra following recurrent penile urethral stricture. Urol Int. 2002; 69:160-161.

15. Larkin GL, Weber JE (1996). Giant urethral calculus. A rare case of urinary retention. J Emeg Med. 1996; 14:707-709.

16. Hyun JS (2018). Clinical Significance of Prostatic Calculi: A Review. World J Mens Health. 2018; 36:15-21.

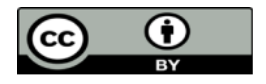

This work is licensed under Creative Commons Attribution 4.0 License

To Submit Your Article Click Here: Submit Manuscript

DOI: $10.31579 / 2690-1919 / 178$
Ready to submit your research? Choose Auctores and benefit from:

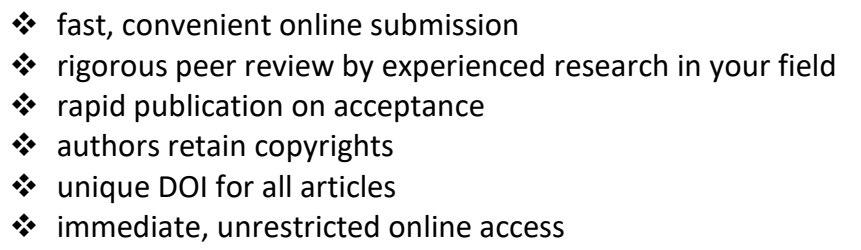

At Auctores, research is always in progress.

Learn more www.auctoresonline.org/journals/journal-of-clinicalresearch-and-reports 